\title{
First report of Kocuria marina spontaneous peritonitis in a child
}

\author{
Gabriel Brändle ${ }^{1,45^{*}}$, Arnaud G L'Huillier ${ }^{2}$, Noémie Wagner ${ }^{2}$, Alain Gervaix' ${ }^{1}$ Barbara E Wildhaber ${ }^{3}$ \\ and Laurence Lacroix ${ }^{1,5^{*}}$
}

\begin{abstract}
Background: Spontaneous bacterial peritonitis (SBP) is a rare affection in the pediatric population. It usually occurs when concurrent conditions are present, such as nephrotic syndrome, peritoneal dialysis or liver disease. We report a case of spontaneous bacterial peritonitis due to Kocuria marina in a 2-year-old child with no underlying risk factor. This is both the first description of an infection caused by this rare pathogen in a child and the first reported case of primary peritonitis caused by K. marina in a patient with no predisposing condition.

Case presentation: A 2 year-old boy presented to the Pediatric Emergency Department with clinical signs of peritonitis. Laparoscopic surgical exploration confirmed purulent, generalized peritonitis without perforation. Culture of the peritoneal fluid revealed the presence of Kocuria marina, a Gram-positive coccoid environmental bacteria. After peritoneal lavage and appropriate antibiotic treatment, the patient improved and was discharged without sequel.

Conclusion: The present report illustrates the first clinical presentation of Kocuria marina SBP in a child with no underlying risk factor. Although never previously described in healthy patients, this pathogen may therefore be considered as a possible cause of SBP in a child. This unusual finding extends the spectrum of infectious diseases caused by Kocuria marina beyond the scope of the previously described susceptible population.
\end{abstract}

Keywords: Spontaneous bacterial peritonitis, Primary peritonitis, Pediatrics, Kocuria, Kocuria marina

\section{Background}

Peritonitis is one of the most frequent abdominal surgical emergency, both in the pediatric and the adult population. It is defined as spontaneous bacterial peritonitis (SBP), or primary peritonitis, when a bacterial infection of the peritoneal cavity is present in the absence of contiguous source of infection [1]. It has been described that 1 to $2 \%$ of all pediatric abdominal emergencies requiring surgical intervention are due to SBP [2]. However, this condition rarely develops in previously healthy children without any underlying medical condition [3]. SBP peaks between 5 and 9 years of age, and is most often described in susceptible patients, especially those prone to ascites (i.e. nephrotic syndrome, chronic liver disease and cardiac insufficiency) or undergoing peritoneal dialysis. Hematogenous inoculation seems to be the main

\footnotetext{
* Correspondence: gabriel.braendle@hcuge.ch; laurence.lacroix@hucge.ch 'Pediatric Emergency Medicine, Child and Adolescent Department, University Hospitals of Geneva, Avenue de la Roseraie 47, CH-1211 Geneva 14, Switzerland

Full list of author information is available at the end of the article
}

pathophysiologic mechanism, but peritoneal spread via the lymphatics, translocation through the intestinal wall, and ascending infection from the female genital tract have also been raised [1]. SBP in children is mainly caused by Streptococcus pneumoniae. However, Gramnegative enteric bacteria (especially Escherichia coli and Klebsiella pneumoniae), Staphylococcus species and Streptococcus pyogenes strains are also common isolated pathogens [4]. Kocuria marina is an exceedingly rare cause of SBP and it has never been encountered to be the causative agent of SBP in a previously healthy patient. Moreover, no pediatric case of SBP due to this pathogen has ever been described.

We report the first case of SBP caused by Kocuria marina in a child with no previous risk factors.

\section{Case presentation}

A 2.5-year-old caucasian boy presented to the Pediatric Emergency Department with a one-day history of lethargy and two episodes of bilious vomiting during the past three hours, without any fever. The symptoms 
appeared two days after he had returned from a 10-day holiday in Crete (Greece), where he ate seafood and fish every day. A cefpodoxime treatment had been introduced 9 days before the admission for an upper respiratory tract infection.

His past medical history revealed mild developmental delay and poorly controlled focal epilepsy, despite valproic acid and clobazam treatment, secondary to an ischemic episode in the neonatal period. No fever or modification of the seizure pattern had been noted by the parents.

Clinical examination revealed a $15.3 \mathrm{~kg}$ body weight conscious but lethargic child lying still in a fetal position. Temperature was $37^{\circ} \mathrm{C}$, heart rate $105 / \mathrm{min}$, and blood pressure 135/88 $\mathrm{mmHg}$. Palpation of the abdomen was tender and bowel sounds were absent. However, no guarding or rebound tenderness was observed. Laboratory work-up showed the following results: white blood cell count $24.8 \mathrm{G} / \mathrm{L}$ with immature neutrophils $6.2 \mathrm{G} / \mathrm{L}$, normal CRP, procalcitonin, AST, ALT and electrolytes. Intravenous lactates were $2.3 \mathrm{mmol} / \mathrm{L}$, and amylase and lipase were elevated (561 U/L and $1074 \mathrm{U} / \mathrm{L}$ respectively).

Abdominal ultrasound showed severe thickening of the intestinal walls in the right lower quadrant, with a large amount of multiloculated peritoneal fluid and hyperechogenic mesenteric fat. The ileocecal valve was hypervascularized. The visualized proximal part of the appendix showed no abnormality and the pancreas also had a normal aspect.
Laparoscopy did not reveal any intra-abdominal abnormality, especially no intestinal wall perforation, but the presence of abundant purulent abdominal fluid and fibrinous membranes in the lower abdomen, thus confirming the diagnosis of primary peritonitis. The appendix was removed. Histology showed no sign of acute appendicitis (Figure 1). The peritoneal fluid grew for a gram-positive, coccoid, aerobic, coagulase-negative, nonencapsulated germ, identified as a Kocuria marina. The organism was grown on BHI (brain heart infusion), a highly nutritious growth medium for fastidious and nonfastidious microorganisms. Blood culture was negative. Unfortunately, peritoneal fluid could not be sent for PCR. Blood PCR was negative for K. marina.

The patient was post-operatively admitted to the intensive care unit and treated with intravenous broad spectrum antibiotics (piperacillin and tazobactam) during 7 days. He gradually improved and was discharged on day 7, with a supplemental 7-day course of oral ciprofloxacin.

\section{Discussion}

SBP is a rare presentation of peritonitis in childhood. Most cases are due to Streptococcus pneumoniae, Escherichia coli or staphylococcal strains [4]. However, in few cases no pathogen can be identified [5]. To our knowledge, this is both the first description of SBP caused by Kocuria marina in a child, and the first description of a

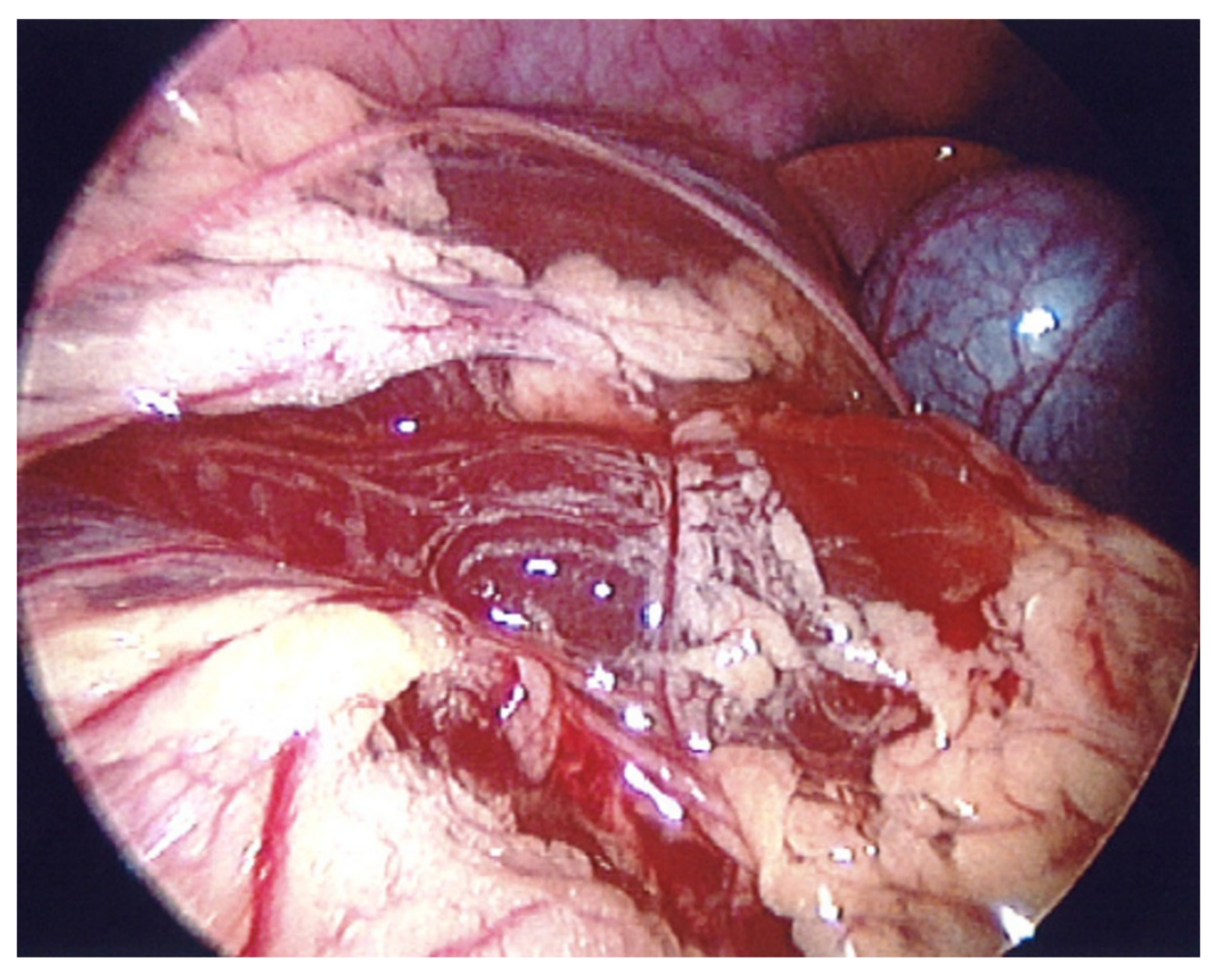

Figure 1 Laparoscopy showing purulent multiloculated abdominal fluid and fibrinous membranes but no intestinal perforation. 
K. marina SBP in a patient with no underlying risk factor.

Kocuria spp are members of the Micrococcaceae family. They are gram-positive, usually aerobic, coccoid, non-encapsulated bacteria. Seventeen species have been recognized so far [6]. They are environmental bacteria that can be encountered in mammals including humans' skin and in the commensal flora of the oropharynx. Certain species (but not K. marina) have been isolated from traditional Korean fermented seafood [7]. Kocuriarelated infections are rare. Bacteremia, peritonitis, brain abscess, endocarditis, cholecystitis and UTI have been described with $K$. rosea, $K$. kristinae, $K$. varians, and $K$. rhizophila (Table 1).

Kocuria marina has been isolated from marine sediments and first identified in 2004 [8]. In 2009, Lee et al. described two cases of primary peritonitis caused by $K$. marina in adult patients undergoing peritoneal dialysis [9]. A small case series reported a positive $K$. marina blood culture in a 57 year-old oncologic patient with a central venous catheter [10]. However, it was considered a contaminant by the authors. We did not find any other report of $K$. marina infection.
In our patient, the organism was identified on peritoneal fluid samples, obtained at the time of surgery. Contamination of the fluid from the skin or from the intestinal content seems very unlikely because of the sterile skin condition at the time of surgery and the absence of visible intestinal perforation. The sample was seeded on the surface of a $5 \%$ sheep blood agar and incubated at $35^{\circ} \mathrm{C}$ in $5 \% \mathrm{CO} 2$. After $48 \mathrm{~h}$ of incubation, the isolate was identified as Kocuria marina by MALDITOF mass spectrometry (score value $=2.014$ ). MALDI target plates were inoculated by picking a freshly grown overnight colony with the tip of a sterile toothpick and smearing the specimen directly onto a ground steel MALDI target plate in a thin film. The microbial film was then overlaid with $1.5 \mu \mathrm{l}$ of a MALDI matrix (a saturated solution of $\alpha$-cyano-4-hydroxy-cinnamic acid in $50 \%$ acetonitrile $-2.5 \%$ trifluoroacetic acid) and allowed to dry at room temperature. Mass spectra were acquired using the MALDI-TOF spectrometer in a linear positive mode (Microflex; Bruker Daltonics). Measured mass spectra ranged from 2,000 to 20,000 Da. Extraction of the peaks from the generated mass spectra and their matching against the reference spectra of the integrated

Table 1 Reported cases of Kocuria spp infections in humans

\begin{tabular}{|c|c|c|c|c|c|}
\hline Species & Clinical presentation & Number of cases & Age (yrs) & Risk factor & Authors \\
\hline \multirow[t]{3}{*}{ K. marina } & Peritonitis & 1 & 3 & None & Brändle, 2014 \\
\hline & Peritonitis & 2 & 57,73 & PD & Lee, 2009 \\
\hline & Bacteremia & 1 & 57 & Cancer, CVC & Lai, 2011 \\
\hline \multirow[t]{2}{*}{ K. rhizophila } & Bacteremia & 1 & 3 & CVC & Moissenet, 2012 \\
\hline & Bacteremia & 1 & 8 & Methylmalonic aciduria & Becker, 2008 \\
\hline \multirow[t]{2}{*}{ K. varians } & Peritonitis & 1 & 70 & PD & Meletis, 2012 \\
\hline & Brain abscess & 1 & 52 & Diabetes & Tsai, 2010 \\
\hline \multirow[t]{5}{*}{ K. rosea } & Endocarditis & 1 & 35 & None & Srinivasa, 2013 \\
\hline & Bacteremia & 1 & 60 & HIV & Corti, 2012 \\
\hline & Bacteremia & 1 & 39 & Hematopoietic stem cell transplantation & Altuntas, 2004 \\
\hline & Peritonitis & 1 & 8 & PD & Dotis, 2012 \\
\hline & Peritonitis & 1 & 56 & PD & Kaya, 2009 \\
\hline \multirow[t]{10}{*}{ K. kristinae } & Bacteremia & 3 & $2,37,68$ & Hypogammaglobulinemia, Cancer, CVC & Lai, 2011 \\
\hline & Endocarditis & 1 & 89 & IBD, post-operative, CVC & Lai, 2011 \\
\hline & UTI & 1 & 20 & Urinary catheter & Tewari, 2013 \\
\hline & Bacteremia & 7 & $<1 \mathrm{yr}$ & Preterm or leukemia, all CVC & Chen, 2013 \\
\hline & Bacteremia & 1 & 68 & Leukemia & Martinaud, 2008 \\
\hline & Bacteremia & 1 & 51 & Ovarian cancer & Basaglia, 2002 \\
\hline & Cholecystitis & 1 & 56 & None & Ma, 2005 \\
\hline & Endocarditis & 1 & 74 & Diabetes & Citro, 2013 \\
\hline & Peritonitis & 1 & 69 & PD & Cheung, 2011 \\
\hline & Peritonitis & 1 & 78 & PD & Carlini, 2011 \\
\hline
\end{tabular}


database provided by the manufacturer was performed with MALDI Biotyper software (Bruker Daltonics). Unfortunately, the peritoneal fluid could not be sent for PCRbased confirmation of the species and antibiotic susceptibilities were not performed.

According to a 2010 review [6] which focuses on antibiotic susceptibilities for Kocuria species, K. marina should respond to ampicillin and other betalactam-based antibiotics while showing a relative resistance to penicillin [10]. At the time of presentation our patient had been treated with oral cephalosporin for 9 days, which might have covered early symptoms and might explain the acute severe clinical presentation.

Another interesting finding is the description of the presence of $K$. marina in seafood and marine sediments. We can assume a potential relationship between the daily fish and seafood consumption over the 10-day period preceding the symptoms in our patient and the peritoneal infection due to this bacterium. Indeed, haematogenous dissemination is frequently described with Kocuria species. In our patient, the pathogen might have been ingested with sea-food, then translocated to mesenteric lymph nodes and to the peritoneal cavity. However, other pathophysiologic mechanisms are possible. Indeed, transient bacteremia following upper respiratory tract colonisation in the context of the upper respiratory tract infection preceding the peritonitis may also be encountered, even if less probable and not documented in this case.

Direct infection through cutaneous breaches associated with sea-bathing seems unlikely in our patient [11].

\section{Conclusion}

The present report illustrates the first clinical presentation of Kocuria marina SBP in a child with no underlying risk factor for peritonitis. Although not previously described in children, this pathogen may be considered as a possible cause of SBP in a child.

\section{Consent}

Written informed consent was obtained from the parents for publication of this case report and any accompanying images. A copy of the written consent is available for review by the Editor of this journal.

\section{Competing interests}

The authors declare that they have no competing interests.

\section{Authors' contributions}

GB and LL established the diagnosis and managed the patient in the Pediatric Emergency Department. BW participated in the surgical management of the patient. AL, NW and AG participated to the literature review. All the authors have contributed to the draft of the article, have read and approved the final manuscript.

\section{Acknowledgments}

We would like to thank Mr. A. Cherkaoui from the Department of Laboratory Medicine, Geneva University Hospital, for his precious help in the description of the method used for the identification of the pathogen.

\section{Author details}

'Pediatric Emergency Medicine, Child and Adolescent Department, University Hospitals of Geneva, Avenue de la Roseraie 47, CH-1211 Geneva 14,

Switzerland. ${ }^{2}$ Pediatric Infectious Diseases, Child and Adolescent Department, University Hospitals of Geneva, Rue Willy Donzé 6, 1205 Geneva, Switzerland. ${ }^{3}$ Pediatric Surgery, Child and Adolescent Department, University Hospitals of Geneva, Rue Willy Donzé 6, 1205 Geneva, Switzerland. ${ }^{4}$ Present address: 37 Bd de la Cluse, CH-1205 Geneva, Switzerland. ${ }^{5}$ Present address: Service d'Accueil et d'Urgences Pédiatriques, Hôpitaux Universitaires des Genève, Avenue de la Roseraie 47, CH-1211 Geneva 14, Switzerland.

Received: 29 June 2014 Accepted: 15 December 2014

Published online: 30 December 2014

\section{References}

1. Garcia-Tsao G: Milestones in liver diseases spontaneous bacterial peritonitis: a historical perspective. J Hepatol 2004, 41(4):522-527.

2. Fowler R: Primary peritonitis: changing aspects 1956-1970. Aust Paediatr J 1971, 7(2):73-83.

3. Freij BJ, Votteler TP, McCracken GH Jr: Primary peritonitis in previously healthy children. Am J Dis Child 1984, 138(11):1058-1061.

4. Rice-Townsend SE, Moss RL, Rangel SJ: Peritonitis. In Pediatric Infectious Disease. 4th edition. Edited by Long SS, Pickerring LK, Prober CG. Philadelphia: Saunders Elsevier; 2012:414-419.

5. Navia MJ, Caroli PL: Primary peritonitis in previously healthy children [in Spanish]. An Pediatr (Barc) 2004, 61(6):554-557.

6. Savini V, Catavitello C, Masciarelli G, Astolfi D, Balbinot A, Bianco A, Febbo F, D'Amario C, D'Antonio D: Drug sensitivity and clinical impact of members of the genus Kocuria. J Med Microbiol 2010, 59(Pt 12):1395-1402.

7. Guan L, Cho KH, Lee JH: Analysis of the cultivable bacterial community in jeotgal, a Korean salted and fermented seafood, and identification of its dominant bacteria. Food Microbiol 2011, 28(1):101-113.

8. Kim SB, Nedashkovskaya Ol, Mikhailov W, Han SK, Kim KO, Rhee MS, Bae KS: Kocuria marina sp. nov., a novel actinobacterium isolated from marine sediment. Int J Syst Evol Microbiol 2004, 54(Pt5):1617-1620.

9. Lee JY, Kim SH, Jeong HS, Oh SH, Kim HR, Kim YH, Lee JN, Kook JK, Kho WG, Bae IK, Shin JH: Two cases of peritonitis caused by Kocuria marina in patients undergoing continuous ambulatory peritoneal dialysis. J Clin Microbiol 2009, 47(10):3376-3378.

10. Lai CC, Wang JY, Lin SH, Tan CK, Wang CY, Liao CH, Chou CH, Huang YT, Lin $\mathrm{HI}$, Hsueh PR: Catheter-related bacteraemia and infective endocarditis caused by Kocuria species. Clin Microbiol Infect 2011, 17(2):190-192.

11. Campbell JR: Peritonitis and intra-abdominal abscess. In Feigin and Cherry's Textbook of Pediatric Infectious Diseases. 7th edition. Edited by Cherry JD, Harrison GJ, Kaplan SL, Steinbach WJ, Hotez PJ. Philadelphia: Saunders Elsevier; 2013:698-705.

\section{Submit your next manuscript to BioMed Central and take full advantage of:}

- Convenient online submission

- Thorough peer review

- No space constraints or color figure charges

- Immediate publication on acceptance

- Inclusion in PubMed, CAS, Scopus and Google Scholar

- Research which is freely available for redistribution 